\title{
OPEM
}

www.opem.org

Oriental Pharmacy and Experimental Medicine 2008 8(3), 302-310

DOI 10.3742/OPEM.2008.8.3.302

\section{Effect of Azadirachta indica flower extract on basal and experimentally elevated blood glucose in rats}

\author{
S Waliullah ${ }^{1}$, Kalim Javed ${ }^{2, *}$, MA Jafri ${ }^{1}$, and S Singh ${ }^{3}$ \\ ${ }^{1}$ Department of Ilmul Advia, Faculty of Medicine (U), Jamia Hamdard, New Delhi, India; ${ }^{2}$ Department of \\ Chemistry, Faculty of Science, Jamia Hamdard, New Delhi, India; ${ }^{3}$ Department of Pharmacology, All India \\ Institute of Medical Sciences, New Delhi, India
}

Received for publication December 13, 2006; accepted December 27, 2007

\section{SUMMARY}

Azadirachta indica A. Juss (N.O. Meliaceae), popularly known, as 'Neem' is an indigenous tree widely available in India. Almost every part of the tree has long been used in Unani system of medicine for the treatment of a variety of human ailments. The flowers have been mentioned as a remedy useful in controlling diabetes mellitus. The present study had been designed to investigate the hypoglycemic/anti-hyperglycemic effects of the methanolic extract of the flowers of A. indica (Gule-Neem) and its different fractions on normal, glucose fed hyperglycemic, adrenaline induced hyperglycemic and alloxan induced diabetic rats. The methanolic extract was resolved into water soluble and water insoluble fractions. Water soluble portion of the methanolic extract was found to possess significant blood sugar lowering effect in glucose-fed and adrenaline-induced hyperglycemic rats but it did not show such effect in normal and alloxan induced mild and severe diabetic rats. Water-soluble portion was fractionated by employing the polarity criterion with ethyl acetate and butanol. The ethyl acetate fraction was further fractionated into phenolic and non-phenolic fractions. Hypoglycemic effect of these fractions was also evaluated. The results suggest that the flowers of $A$. indica contain at least two different constituents, responsible for the said activity. These investigations validate the use of flowers of A. indica in diabetes by Unani physicians.

Key words: Neem; Azadirachta indica; Anti-hyperglycemic; Diabetes; Adrenalineinduced hyperglycemia

\section{INTRODUCTION}

The tree Azadirachta indica A Juss (N.O. Meliaceae), popularly known as 'Neem', is an indigenous plant widely available in India. Almost every part of the tree has long been used in Unani system of

\footnotetext{
*Correspondence: Kalim Javed, Department of Chemistry, Faculty of Science, Jamia Hamdard, New Delhi - 110 062, India. E-mail: kjaved@jamiahamdard.ac.in, kjavedchem @yahoo.co.in
}

medicine for the treatment of a variety of human ailments (Rahman and Jairajpuri, 1996). Flowers have been mentioned as a remedy useful in getting rid of intestinal worms, bile, phlegm, boils and bilious fever. Gargling of decoction of the flowers provides strength to gums and teeth. The flowers of this plant are valued for ophthalmic use also. Classical literature survey revealed that only the flowering part of this plant is reputed for controlling diabetes mellitus (Azam, 1899; Ghani, 1920). 
There are several reports on this plant to have various biological activities (Biswas et al., 2002). Relevant literature reveals that a significant hypoglycemic activity was observed by oral administration of aqueous extract of tender leaves in fasting rabbits and rats and, of a lesser magnitude in guinea pigs (Luscombe and Taha, 1974). Intravenous administration of aqueous extract of the Neem leaves resulted in significant decrease in blood glucose levels in both normoglycemic and adrenaline induced hyperglycemic dogs (Murty et al., 1978). It has been reported that the extract obtained by the extraction of Neem leaves with boiling water exhibited a significant hypoglycemic activity in streptozotocin (Chakraborty and Poddar, 1984), alloxan induced diabetic (El-Hawary, 1990) and normal rats (Chakraborty et al., 1989; El-Hawary, 1990) while water soluble portion of the alcoholic extract of the leaves was found failed to possess such type of effect in normal and streptozotocininduced diabetic rats. However it showed significant blood sugar lowering effect in glucose-fed and adrenaline-induced hyperglycemic rats (Chattopadhyay et al., 1987). It was suggested that the blood sugar lowering effect might be due to its antiserotonin activity and insulin releasing pancreatic effect (Chattopadhyay, 1993, 1996, 1999; Chattopadhyay et al., 1993a,b). A moderate hypoglycemic activity was observed by administering the leaves extract to streptozotocin-induced diabetic rabbits (Santoshkumari and Devi, 1990). Kaushik et al. (1999) reported that the administration of the alcoholic extract of Neem in a single oral dose for four weeks to alloxan induced diabetic rabbits improved the blood glucose level and lipid profile significantly. Aqueous extract of fresh leaves reversed diabetic retinopathy in streptozotocininduced diabetic rats (Hussain, 2002). A significant hypoglycemic activity was observed by feeding the seed oil in a dose of $2.5 \mathrm{ml} / \mathrm{kg}$ or nimbidin (200 $\mathrm{mg} / \mathrm{kg}$ ) to the fasting rabbits. In glucose tolerance test, $1 \mathrm{ml}$ of Neem leaf decoction (prepared by boiling $10 \mathrm{~g}$ dried leaves in $100 \mathrm{ml}$ of water), $2.5 \mathrm{ml}$ of its seed oil, and $200 \mathrm{mg}$ of nimbidin each significantly delayed the peak rise in blood sugar after glucose administration. Both the oil and nimbidin were half as potent as tolbutamide (Pillai and Santhakumari, 1981). Neem oil was found to possess significant blood glucose lowering effect in adrenaline-induced hyperglycemic rats and, glucosefed hyperglycemic, alloxan-induced diabetic and normal rabbits (Sharma, et al., 1983). The petroleum ether extract of Neem seed produced significant blood glucose lowering activity in normal as well as alloxan-induced (mild and severe) diabetic rats after $3 \mathrm{~h}$ and $6 \mathrm{~h}$. The decrease in blood glucose level was more pronounced in the mild hyperglycemic rats (Dixit et al., 1986). An intraperitoneal injection of $20 \mathrm{mg} / \mathrm{kg}$ of Neem seed oil in intact mice resulted in decrease in blood sugar level. However, the decrease was more pronounced in streptozotocin-induced diabetic mice (Purohit et al., 1990). The administration of Neem kernel powder significantly decreased the concentration of blood glucose of alloxan induced diabetic rabbits (Bopanna et al., 1997). Recently it has been reported that petroleum ether extracts of kernel and husk prevent oxidative stress caused by streptozotocin in adult male Wistar rats' heart and erythrocytes (Gupta, et al., 2004).

The flowers of Azadirachta indica have been reported to contain myricetin, quercetin, kaempferol, melicitrin (myricetin-3-L-arabinoside), quercetin-3-galactoside and kaempferol-3-glucoside (Subramanian and Nair, 1972). Other constituents such as cholesterol (Siddiqui et al., 1986a), stigmasterol (Siddiqui et al., 1986b) and Neeflone (Nanduri and Banstola, 1995) were discovered. A report on the analysis of essential oil is also available (Subramanian and Rangaswamy, 1947).

The present study has been designed to investigate the hypoglycemic/anti-hyperglycemic effects of the extract(s) of Gule-Neem on normal, glucose fed hyperglycemic, adrenaline induced hyperglycemic and alloxan induced diabetic rats. An attempt has also been made to find out the possible constituents 
responsible for the blood sugar lowering effect. The results were compared with gliclazide, a clinically used anti-diabetic drug.

\section{MATERIALS AND METHODS}

\section{Plant material}

The abortive flowers of Azadirachta indica were collected from the places under the trees growing in the campus of Jamia Hamdard, New Delhi, during the months of April - May. The plant material was further dried under shade in open air. The authenticity of the collected material was established by matching with the specimen available in the Pharmacognosy section of Ilmul-Advia department. The voucher specimen (GN - 2000) has been deposited in the same section of the department.

\section{Preparation of extracts (Harborne, 1973)}

The dried abortive flowers of Azadirachta indica (500 g) were exhaustively extracted with hot methanol four times. All the methanolic extracts were combined together. Recovery of solvent left a greenish viscous mass $(44 \mathrm{~g})$ and was coded as $\mathrm{M}$. The extract $M$ was taken up in water and filtered to give the water insoluble (W-INS) and water-soluble (W-S) fractions, which constituted approximately $12.68 \mathrm{~g}$ and $30.32 \mathrm{~g}$ respectively. The W-S fraction after re-dissolving in distilled water was successively subjected to liquid-liquid extraction with ethyl acetate and n-butanol. The ethyl acetate and nbutanol layers were dried separately over anhydrous sodium sulphate and filtered. The solvents (ethyl acetate and Butanol) were removed by distillation under reduced pressure to give LL-EA (2.150 g) and LL-B (12.930 g) respectively. The W-S fraction left after liquid-liquid extraction with ethyl acetate and butanol was evaporated to dryness to give LLW $(13.080 \mathrm{~g})$. The LL-EA was fractionated into phenolics [LL-EA-P] and non-phenolics [LL-EA$\mathrm{NP})$ fractions by the following method.

LL-EA ( $1 \mathrm{~g})$ was dissolved in ethyl alcohol. A solution of lead acetate $(20 \% \mathrm{w} / \mathrm{v})$ was added drop wise till complete precipitation of phenolic compounds took place. It was digested for few minutes on water bath to let the precipitate settle down and then filtered (filtrate coded as F). The precipitate was washed with some volume of ethanol, dried, powdered and suspended in alcohol. To it $\mathrm{H}_{2} \mathrm{~S}$ gas was bubbled to decompose precipitate into $\mathrm{PbS}$ and phenolics. The black precipitate of $\mathrm{PbS}$ was removed by filtration and filtrate was concentrated under reduced pressure. It was subjected to vacuum distillation three times after adding fresh quantity of alcohol each time, to get rid of all the $\mathrm{H}_{2} \mathrm{~S}$ gas. The residue thus obtained was coded as LL-EA-P ( $0.250 \mathrm{~g})$. The lead acetate present in the filtrate $(\mathrm{F})$ was removed by passing $\mathrm{H}_{2} \mathrm{~S}$ gas. The black precipitate of $\mathrm{PbS}$ was removed by filtration. The filtrate thus obtained was evaporated to dryness under reduced pressure to give non-phenolic fraction and was coded as LLEA-NP $(0.600 \mathrm{~g})$. The amount $0.150 \mathrm{~g}$ could not be recovered. It may be due to irreversible adsorption of LL-EA on the surface of lead sulphide precipitate.

\section{Animals}

All the experiments were carried out in albino rats of Wistar strain (either sex) obtained from Central Animal House of the university. Animals described as fasted were deprived of food for at least $16 \mathrm{~h}$ but allowed free access to water. Carboxymethylcellulose $(\mathrm{CMC} 1 \% \mathrm{w} / \mathrm{v})$ in distilled water was used as vehicle for dosing in all the experiments. Three males and three females were taken in each group in entire the study. Gliclazide $(50 \mathrm{mg} / \mathrm{kg}$ ) was used as reference drug (Sha et al., 2006).

\section{Experimental procedure}

Effect of the methanolic extract $(\mathrm{M})$ and its different fractions (W-INS, W-S, LL-EA, LL-B, LL-W, LL-EA-P, and LL-EA-NP) on adrenaline induced hyperglycemic rats.

In experiment $A$, the albino rats $(130-150 \mathrm{~g})$ fasted overnight were classified into three groups 
Table 1. Effect of the methanolic extract $(\mathrm{M})$ and its different fractions (W-INS, W-S, LL-EA, LL-B, LL-W, LL-EA$\mathrm{P}$, and LL-EA-NP) on adrenaline induced hyperglycemic rats

\begin{tabular}{|c|c|c|c|c|c|}
\hline \multirow{2}{*}{ Expt. } & \multirow{2}{*}{ Treatment } & \multicolumn{4}{|c|}{ Blood glucose level mg/dl } \\
\hline & & $0 \mathrm{~min}$ & $30 \mathrm{~min}$ & $60 \mathrm{~min}$ & $90 \mathrm{~min}$ \\
\hline \multirow{3}{*}{ A } & Vehicle (10 ml/kg) & $63.50 \pm 1.17$ & $121.83 \pm 1.55$ & $133.50 \pm 0.99$ & $125.50 \pm 1.60$ \\
\hline & Gliclazide(50 mg/kg) & $29.50 \pm 1.33$ & $82.83 \pm 3.10^{* * *}$ & $72.50 \pm 3.39$ & $51.50 \pm 3.27^{* * *}$ \\
\hline & M (1000 mg/kg) & $68.33 \pm 2.17$ & $105.33 \pm 3.25^{* *}$ & $104.66 \pm 4.91^{* * *}$ & $103.16 \pm 4.35$ \\
\hline \multirow{4}{*}{ B } & Vehicle $(10 \mathrm{ml} / \mathrm{kg})$ & $68.16 \pm 1.57$ & $100.38 \pm 1.06$ & $125.83 \pm 2.77$ & $142.16 \pm 2.05$ \\
\hline & Gliclazide (50 mg/kg) & $47.05 \pm 0.22$ & $52.66 \pm 1.35^{* * *}$ & $79.00 \pm 1.52^{* * *}$ & $94.00 \pm 1.87^{* * *}$ \\
\hline & W-INS (1,000 mg/kg) & $69.00 \pm 1.17$ & $98.23 \pm 1.58$ & $129.50 \pm 1.43$ & $140.30 \pm 1.81$ \\
\hline & W-S $(1,000 \mathrm{mg} / \mathrm{kg})$ & $61.00 \pm 0.96$ & $65.33 \pm 1.54^{* * *}$ & $63.50 \pm 1.52^{* * *}$ & $81.00 \pm 1.18^{* * *}$ \\
\hline \multirow{5}{*}{$\mathrm{C}$} & Vehicle $(10 \mathrm{ml} / \mathrm{kg})$ & $63.50 \pm 2.01$ & $136.00 \pm 0.57$ & $176.00 \pm 1.52$ & $179.00 \pm 1.19$ \\
\hline & Gliclazide(50 mg/kg) & $44.00 \pm 0.57$ & $106.00 \pm 3.27^{* * *}$ & $129.00 \pm 1.51^{* * * *}$ & $128.00 \pm 2.47^{\text {**** }}$ \\
\hline & LL-EA (77 mg/kg) & $67.50 \pm 1.52$ & $104.00 \pm 3.47^{* * * *}$ & $129.00 \pm 2.92^{* * *}$ & $116.83 \pm 3.45^{* * *}$ \\
\hline & LL-B (259 mg/kg) & $67.33 \pm 2.02$ & $102.66 \pm 4.55^{* * * *}$ & $170.00 \pm 5.26$ & $158.50 \pm 4.03^{* * *}$ \\
\hline & LL-W (264 mg/kg) & $69.83 \pm 2.21$ & $117.16 \pm 0.94^{* * *}$ & $164.66 \pm 4.88^{*}$ & $155.83 \pm 4.48^{* * *}$ \\
\hline \multirow{4}{*}{$\mathrm{D}$} & Vehicle $(10 \mathrm{ml} / \mathrm{kg})$ & $78.66 \pm 2.48$ & $116.16 \pm 1.62$ & $188.16 \pm 1.88$ & $188.83 \pm 1.95$ \\
\hline & Gliclazide (50 mg/kg) & $34.16 \pm 2.08$ & $67.5 \pm 0.56^{* * *}$ & $143.33 \pm 1.62^{* * * *}$ & $169.66 \pm 1.05^{* * * *}$ \\
\hline & LL-EA-P (77 mg/kg) & $65.33 \pm 1.35$ & $66.00 \pm 2.92^{* * *}$ & $167.66 \pm 4.35^{* * *}$ & $186.83 \pm 4.49$ \\
\hline & LL-EA-NP (77 mg/kg) & $76.33 \pm 0.88$ & $58.50 \pm 2.04^{* * *}$ & $130.00 \pm 1.48^{* * *}$ & $171.50 \pm 0.22^{* \star * \star}$ \\
\hline
\end{tabular}

Values are expressed as mean \pm S.E.M. $(n=6)$. Statistically significant difference with respect to the vehicle ${ }^{*} P<$ $0.05,{ }^{* *} P<0.01,{ }^{* * *} P<0.001$.

of six animals each. Group-I was fed with vehicle (CMC $1 \% \mathrm{w} / \mathrm{v}$ in distilled water) in a volume of 10 $\mathrm{ml} / \mathrm{kg}$. The methanolic extract $(\mathrm{M})$ in the dose of $1000 \mathrm{mg} / \mathrm{kg}$ (random dose) and the reference drug gliclazide $(50 \mathrm{mg} / \mathrm{kg})$ suspended in the vehicle were administered p.o. in a volume of $10 \mathrm{ml} / \mathrm{kg}$ to II and III groups respectively. Adrenaline hydrochloride $(0.5 \mathrm{mg} / \mathrm{kg})$ was administered, i.p. to all the rats $30 \mathrm{~min}$ after dosing (Chattopadhyay et al., 1987). Blood samples were collected from retro-orbital plexus just prior to and at 30, 60 and $90 \mathrm{~min}$ after the administration of adrenaline hydrochloride and blood glucose levels were measured (Table 1, Expt-A).

The same protocol was adopted for experiment $\mathrm{B}, \mathrm{C}$ and D. In experiment-B the animals of two different groups were treated with W-INS (1,000 $\mathrm{mg} / \mathrm{kg}$ a random dose) and W-S (1,000 mg/ $\mathrm{kg}$ a random dose) respectively. In experiment- $C$, the animals of three different groups were treated with LL-EA (77 mg/kg), LL-B (259 mg/kg) and LL-W
(264 mg/kg) respectively. In experiment-D the animals of two different groups were pre-treated with LL-EA-P $(77 \mathrm{mg} / \mathrm{kg}$ ) and LL-EA-NP $(77 \mathrm{mg}$ / $\mathrm{kg}$ ) respectively. Each experiment (B, C and D) had its own control (vehicle, $10 \mathrm{ml} / \mathrm{kg}$ ) and standard (gliclazide, $50 \mathrm{mg} / \mathrm{kg}$ ) groups (Table 1, Expt-B, C and D).

Effect of W-INS, W-S, LL-EA, LL-B, and LL-W in glucose fed hyperglycaemic rats.

In experiment- $A$, the fasted rats were divided into four groups of six animals each. Group-I served as control, received vehicle $(1 \% \mathrm{CMC}$ in distilled water, $10 \mathrm{ml} / \mathrm{kg}$, p.o.). A dose of $(50 \mathrm{mg} / \mathrm{kg})$ of gliclazide, W-INS, and W-S $(1,000 \mathrm{mg} / \mathrm{kg}$ each) suspended in vehicle in volume of $10 \mathrm{ml} / \mathrm{kg}$ were administered to the animals of II, III and IV groups respectively. All the animals were given glucose ( $3 \mathrm{~g} / \mathrm{kg}$, p.o.) $30 \mathrm{~min}$ after dosing (Chattopadhyay et al., 1987). Blood samples were collected from the retro-orbital plexus just prior to and 30, 60, and 90 min after the glucose loading and the glucose 
Table 2. Effect of W-INS, W-S, LL-EA, LL-B, and LL-W in glucose fed hyperglycemic rats

\begin{tabular}{|c|c|c|c|c|c|}
\hline \multirow{2}{*}{ Expt. } & \multirow{2}{*}{ Treatment } & \multicolumn{4}{|c|}{ Blood glucose level mg/dl } \\
\hline & & $0 \mathrm{~min}$ & $30 \mathrm{~min}$ & $60 \mathrm{~min}$ & $90 \mathrm{~min}$ \\
\hline \multirow{4}{*}{ A } & Vehicle $(10 \mathrm{ml} / \mathrm{kg})$ & $59.00 \pm 1.06$ & $134.16 \pm 3.36$ & $113.83 \pm 3.07$ & $110.50 \pm 2.92$ \\
\hline & Gliclazide $(50 \mathrm{mg} / \mathrm{kg})$ & $31.33 \pm 1.89$ & $70.66 \pm 2.82^{*}$ & $36.50 \pm 2.60^{*}$ & $56.33 \pm 2.99^{*}$ \\
\hline & W-INS (1,000 mg/kg) & $66.33 \pm 1.77$ & $128.34 \pm 2.58$ & $116.00 \pm 1.48$ & $125.23 \pm 1.89$ \\
\hline & W-S (1,000 mg/kg) & $70.00 \pm 2.92$ & $93.33 \pm 2.60^{*}$ & $122.00 \pm 2.73$ & $138.50 \pm 1.87$ \\
\hline \multirow{5}{*}{ B } & Vehicle $(10 \mathrm{ml} / \mathrm{kg})$ & $57.33 \pm 1.33$ & $88.16 \pm 2.65$ & $90.66 \pm 3.01$ & $90.33 \pm 1.38$ \\
\hline & Gliclazide $(50 \mathrm{mg} / \mathrm{kg})$ & $32.33 \pm 2.59$ & $51.50 \pm 3.23^{*}$ & $73.83 \pm 2.11^{*}$ & $71.50 \pm 3.09^{*}$ \\
\hline & LL-EA (77 mg/kg) & $54.83 \pm 0.94$ & $85.50 \pm 1.72$ & $85.50 \pm 2.45$ & $85.50 \pm 2.75$ \\
\hline & LL-B (259 mg/kg) & $60.50 \pm 2.17$ & $86.83 \pm 3.70$ & $87.66 \pm 1.25$ & $89.50 \pm 2.58$ \\
\hline & LL-W (264 mg/kg) & $51.33 \pm 1.33$ & $90.00 \pm 3.15$ & $90.66 \pm 2.66$ & $91.83 \pm 2.97$ \\
\hline \multirow{5}{*}{ C } & Vehicle $(10 \mathrm{ml} / \mathrm{kg})$ & $75.33 \pm 2.29$ & $113.83 \pm 1.42$ & $114.00 \pm 0.96$ & $109.50 \pm 3.33$ \\
\hline & Gliclazide $(50 \mathrm{mg} / \mathrm{kg})$ & $48.83 \pm 1.24$ & $61.50 \pm 1.60^{*}$ & $64.83 \pm 2.45^{*}$ & $63.23 \pm 3.78^{*}$ \\
\hline & LL-EA (230 mg/kg) & $78.16 \pm 3.00$ & $113.00 \pm 6.14$ & $120.50 \pm 7.37$ & $118.22 \pm 4.55$ \\
\hline & LL-B (777 mg/kg) & $75.83 \pm 0.65$ & $95.00 \pm 2.06^{*}$ & $106.50 \pm 0.76$ & $112.34 \pm 5.45$ \\
\hline & LL-W (792 mg/kg) & $77.16 \pm 1.88$ & $96.66 \pm 1.72^{*}$ & $95.50 \pm 2.77^{*}$ & $100.60 \pm 6.66$ \\
\hline
\end{tabular}

Values are expressed as mean \pm S.E.M. $(n=6)$. Statistically significant difference with respect to the vehicle ${ }^{*} P<$ 0.001 .

levels were measured (Table 1, Expt-A). The same protocol was adopted for experiment B and C. In each set of experiment, the vehicle, and reference drug, gliclazide, were administered to two different groups in similar quantities as mentioned above. In experiment $B$, three different groups were pretreated with LL-EA (77 mg/kg), LL-B (259 mg/kg) and LL-W (264 mg/kg) respectively (Table 2, ExptB) while in experiment- $C$ three different groups received same fractions in three folds (Table 2, Expt-C).

Effect of W-INS and W-S on blood glucose levels in normal fasted rats

Fasted rats were divided into four groups of six animals each. Group-I received only vehicle $(1 \%$ $\mathrm{CMC}$ in distilled water, $10 \mathrm{ml} / \mathrm{kg}$, p.o.) and served as control. Group-II was administered gliclazide (50 mg/kg, p.o.) suspended in the vehicle. The test drugs W-INS (1,000 mg/kg) and W-S (1,000 mg/ $\mathrm{kg}$ ) suspended in the vehicle were given orally to the animals of group-III and IV respectively. Blood samples were collected from the retro-orbital plexus just prior to and at 1, 2 and $3 \mathrm{~h}$ after dosing to measure the blood glucose level (Table 3).

\section{Induction of experimental diabetes by alloxan monohydrate}

Rats were made diabetic by giving a single intraperitoneal injection of freshly dissolved alloxan

Table 3. Effect of W-INS and W-S on blood glucose levels in normal fasted rats

\begin{tabular}{lccc}
\hline \multirow{2}{*}{ Treatment } & \multicolumn{3}{c}{ Blood glucose level mg/dl } \\
\cline { 2 - 4 } & $0 \mathrm{~h}$ & $1 \mathrm{~h}$ & $2 \mathrm{~h}$ \\
\hline Vehicle $(10 \mathrm{ml} / \mathrm{kg})$ & $59.00 \pm 2.28$ & $68.50 \pm 0.76$ & $68.50 \pm 0.56$ \\
Gliclazide $(50 \mathrm{mg} / \mathrm{kg})$ & $71.00 \pm 1.06$ & $38.33 \pm 2.40^{*}$ & $41.83 \pm 2.19^{*}$ \\
W-INS $(1,000 \mathrm{mg} / \mathrm{kg})$ & $71.50 \pm 2.98$ & $76.66 \pm 2.24$ & $72.33 \pm 1.70$ \\
W-S $(1,000 \mathrm{mg} / \mathrm{kg})$ & $60.33 \pm 2.29$ & $66.55 \pm 1.72$ & $65.66 \pm 1.49$ \\
\hline
\end{tabular}

Values are expressed as mean \pm S.E.M. $(n=6)$. Statistically significant difference with respect to the vehicle ${ }^{*} P<$ 0.001 . 
monohydrate $10 \%(\mathrm{w} / \mathrm{v})$ in normal saline in a dose of $200 \mathrm{mg} / \mathrm{kg}$ (Dixit et al., 1986). At $72 \mathrm{~h}$ after the injection of alloxan monohydrate, fasting glucose was measured to identify the diabetic rats. Animals that did not develop hyperglycaemia $(40 \%)$ were rejected. Diabetic rats were classified into two group i.e. mild diabetic (fasting blood glucose level less than $300 \mathrm{mg} / \mathrm{dl}$ ) and severe diabetic (fasting blood glucose level more than $400 \mathrm{mg} / \mathrm{dl}$ ).

\section{Effect of the W-S on blood glucose level in alloxan} induced mild diabetic rats

Mild diabetic rats were classified into three groups of six animals each.

Group I: Animals were administered only vehicles $(10 \mathrm{ml} / \mathrm{kg})$ and served as control.

Group II: Animals were administered reference drug i.e. gliclazide $(50 \mathrm{mg} / \mathrm{kg})$ suspended in vehicle.

Group III: Animals were administered W-S (1,000 $\mathrm{mg} / \mathrm{kg}$ ) dissolved in vehicle.

Blood samples were collected for the estimation of glucose concentration just prior to and at 1 and 2 $\mathrm{h}$ after dosing (Table 4).

Effect of the W-S on blood glucose levels in alloxan induced severe diabetic rats

Severe diabetic rats were divided into three groups of six rats each. The vehicle, reference drug (gliclazide) and the test drug (W-S) were administered to group I, II, and III respectively in similar quantities as mentioned in the above experiment. Blood samples were taken before the dosing and at $1 \mathrm{~h}$ and $2 \mathrm{~h}$ thereafter (Table 5).

\section{Blood sugar estimation}

The blood sugar estimation was done by Dubowski's method (1962).

\section{Statistical analysis}

Statistical significance was assessed by student' $t$ test.

\section{RESULTS AND DISCUSSION}

It is known that adrenaline increases the blood sugar level by enhancing hepatic glycogenolysis and by reducing the uptake of glucose by peripheral tissues. In the present investigation, a significant inhibition was observed in the rise of blood glucose concentration on administration of the methanolic extract $(1,000 \mathrm{mg} / \mathrm{kg}$, a random dose) in adrenaline induced hyperglycemic rats at 30 and $60 \mathrm{~min}$ (Table 1, Expt-A). The methanolic extract was resolved into water-soluble (W-S) and water insoluble (WINS) fractions. W-S and W-INS in the dose of 1,000

Table 4. Effect of W-INS and W-S on blood glucose levels in alloxan induced mild diabetic rats

\begin{tabular}{lccc}
\hline \multirow{2}{*}{ Treatment } & \multicolumn{3}{c}{ Blood glucose level mg/dl } \\
\cline { 2 - 4 } & $0 \mathrm{~h}$ & $1 \mathrm{~h}$ & $2 \mathrm{~h}$ \\
\hline Vehicle $(10 \mathrm{ml} / \mathrm{kg})$ & $278.33 \pm 4.33$ & $277.66 \pm 2.86$ & $279.33 \pm 2.58$ \\
Gliclazide $(50 \mathrm{mg} / \mathrm{kg})$ & $262.66 \pm 7.05$ & $220.66 \pm 5.20^{*}$ & $186.33 \pm 5.23^{*}$ \\
W-S $(1,000 \mathrm{mg} / \mathrm{kg})$ & $265.33 \pm 3.71$ & $272.66 \pm 4.05$ & $267.33 \pm 9.24$ \\
\hline
\end{tabular}

Values are expressed as mean \pm S.E.M. $(\mathrm{n}=6)$. Statistically significant difference with respect to the vehicle ${ }^{*} P<0.001$.

Table 5. Effect of W-INS and W-S on blood glucose levels in alloxan induced severe diabetic rats

\begin{tabular}{lccc}
\hline \multirow{2}{*}{ Treatment } & \multicolumn{3}{c}{ Blood glucose level mg/dl } \\
\cline { 2 - 4 } & $0 \mathrm{~h}$ & $1 \mathrm{~h}$ & $2 \mathrm{~h}$ \\
\hline Vehicle $(10 \mathrm{ml} / \mathrm{kg})$ & $456.32 \pm 9.21$ & $460.13 \pm 8.23$ & $460.00 \pm 6.21$ \\
Gliclazide $(50 \mathrm{mg} / \mathrm{kg})$ & $432.30 \pm 8.62$ & $429.21 \pm 15.92$ & $426.33 \pm 16.63$ \\
W-S $(1,000 \mathrm{mg} / \mathrm{kg})$ & $452.52 \pm 14.64$ & $449.39 \pm 12.02$ & $458.23 \pm 18.29$
\end{tabular}

Values are expressed as mean \pm S.E.M. $(\mathrm{n}=6)$. 
$\mathrm{mg} / \mathrm{kg}$ each (random dose) have also been investigated for sugar-lowering effect in adrenaline induced hyperglycemic rats. Results indicated that the water-soluble methanolic extract (W-S) exerted significant inhibitory effect at 30,60, and $90 \mathrm{~min}$ respectively. But the water insoluble methanolic extract (W-INS) failed to inhibit the increase in blood sugar level in adrenaline induced hyperglycemic rats (Table 1, Expt-B).

Effects of oral administration of the W-S and W-INS (1000 mg/kg in each) have also been investigated in glucose fed hyperglycemic rats. The W-S significantly prevented the rise in blood glucsoe level only at $30 \mathrm{~min}$, but W-INS did not inhibit the elevation of blood sugar level (Table 2, Expt-A).

Alloxan, a substance structurally related to uric acid induces diabetes by destroying $\beta$-cells and impairing the renal function. In the present study, rats were made diabetic by giving a single i.p. injection of alloxan monohydrate and classified into mild and severe diabetics. The WS did not produce hypoglycemia neither in mild (Table 4) nor in severe diabetic rats (Table 5). On the other hand gliclazide showed significant anti-hyperglycemic effect in mild diabetic rats but did not bring down the blood glucose level of severe diabetic rats. W-S was found failed to produce hypoglycemia in fasted normal rats also (Table 3). It is well known that clinically used sulphonylurea drug (gliclazide etc.) produce hypoglycemia by stimulating insulin release from pancreatic $\beta$-cells in normal subjects as well as in diabetics. But they remain ineffective in totally insulin deficient patients. Considering these factors together, it appears that the W-S probably failed to stimulate the b-cells to release insulin.

As discussed above, the WS was found to possess anti-hyperglycemic activity only in adrenaline treated or glucose fed hyperglycemic rats. At the present juncture it is not possible to pinpoint the exact mechanism of anti-hyperglycemic action of the WS. However, based on the earlier reports some suggestions can be made for its possible mechanism. It has been reported that water soluble portion of the alcoholic extract of Azadirachta indica leaves possess significant blood glucose lowering effect in glucose fed and adrenaline induced hyperglycemic rats but failed to possess such type of effect in normal and streptozotocin induced diabetic rats (Chattopadhyay et al., 1987). These findings in leaves are very similar to our findings in flowers. In another report Chattopadhyay et al. (1993a) established that water-soluble portion of the alcoholic extract of Azadirachta indica leaves possesses anti-serotonin activity. Serotonin has been reported to have inhibitory effect on insulin release especially cAMP mediated insulin release in response to adrenaline injection or glucose load (Feldman et al., 1972). Recently, the effect of water-soluble portion of the alcoholic extract of Azadirachta indica leaves has been studied on serotonin inhibition in glucose mediated insulin release in rat pancreas and has been reported that it blocks the inhibitory effect of serotonin significantly on insulin secretion, mediated by glucose (Chattopadhyay, 1999). Thus it may reasonably be postulated that the test WS blocks the inhibitory action of the intracellular compartmentalized serotonin pool in pancreatic islet cells and thereby potentiate the insulin release, triggered off by adrenaline injection or glucose feed. But it needs further exploration.

W-S after redisolving in distilled water was partitioned by employing the polarity criterion with ethyl acetate and butanol successively. The fractions thus obtained were coded as LL-EA and LL-B respectively. W-S fraction remained after liquid-liquid extraction with ethyl acetate and butanol was coded as LL-W. All the fractions (LL-EA, LL-B, and LL-W) corresponding to $1 \mathrm{~g}$ dried W-S fraction were investigated for anti-hyperglycemic effects in adrenaline induced and glucose fed hyperglycemic rats to determine the fraction containing active constituent(s). In adrenaline treated rats, all the fractions (LL-EA, LL-B, and LL-W) prevented significantly the rise in blood glucose concentration but the effect of LL-EA was more pronounced. The LL-EA remained effective until 
the end of the studies at the $90 \mathrm{~min}$ (Table 1, Expt-C).

LL-EA gave blue-greenish colouration with alcoholic $\mathrm{FeCl}_{3}$ solution and magenta colour with $\mathrm{Mg}-\mathrm{HCl}$ indicating the presence of phenolic/ flavonoid compounds. LL-EA was fractionated into phenolic (LL-EA-P) and non-phenolic (LL-EA-NP) fraction by precipitating with lead acetate and then decomposing the lead complex by $\mathrm{H}_{2} \mathrm{~S}$ gas. LL-EA$\mathrm{NP}$ gave no coloration with alcoholic $\mathrm{FeCl}_{3}$. Both the fractions (LL-EA-P and LL-EA-NP) were tested in the same doses, chosen randomly, in adrenaline induced hyperglycemic rats. Both were found to be active. However, non-phenolic fraction (LL-EANP) showed greater activity (Table 1, Expt-D). Thus, at present, it may be postulated that the phenolic and non-phenolic constituents present in LL-EA are collectively responsible for preventing the rise of blood sugar level in adrenaline induced hyperglycemic rats.

In glucose fed hyperglycemic rats, oral administration of W-S $(1 \mathrm{~g} / \mathrm{kg})$ showed inhibition at $30 \mathrm{~min}$ (Table 2, Expt-A) but its fractions (LL-EA, LL-B, LL-W) corresponding to $1 \mathrm{~g}$ of W-S did not show anti-hyperglycemic effect (Table 2, Expt-B). The reason behind this might be the distribution of the effective dose among LL-EA, LL-B and LL-W. The experiment was again conducted with these fractions (but the doses were given in three folds) in glucose fed hyperglycemic rats with a view to find out the fraction that contains active principle. The fraction LL-B and LL-W both prevented significantly the rise of blood glucose level but the effect of LL-W was more pronounced and remained same at $60 \mathrm{~min}$ (Table 2, Expt-C).

The observations that LL-B and LL-W showed significant anti-hyperglycemic effects in glucose fed and adrenaline induced hyperglycemic rats and the finding that LL-EA showed significant anti-hyperglycemic effect only in adrenaline induced hyperglycemic rats led to the conclusion that flowers of Azadirachta indica contain atleast two different constituents responsible for the said activities. At present we may conclude that flowers of
Azadirachta indica, in totality, is effective in reducing the enhanced blood glucose level under our experimental conditions.

\section{ACKNOWLEDGEMENTS}

The authors are thankful to the department of I.S.M and $\mathrm{H}$ (Ministry of Health and Family Welfare, Govt. of India) for providing financial support to our dept. (IImul Advia) and a fellowship to one of the authors (SW).

\section{REFERENCES}

Azam K. (1899) Muheet-e-Azam vol. IV part-2, p. 177179, Nizami press, Kanpur, India

Biswas K, Chattopdhyay I, Banerjee RK, Bandyopadhyay U. (2002) Biological activities and medicinal properties of neem (Azadirachta indica). Curr. Sci. 82, 1336-1345.

Bopanna KN, Kannan J, Gadgie S, Balaraman R, Rathod S. (1997) Anti-diabetic and anti-hyperglycemic effect on Neem seed kernels powder on alloxan induced diabetic rabbits. Indian J. Pharm. 29, 162-167.

Chakraborty T, Poddar G. (1984) Herbal drugs in diabetes part: I, Hypoglycemic activity of indigenous plants in streptozotocin induced diabetic rats. J. Inst. Chem. India 56, 20-22.

Chakraborty T, Varotta L, Podder G. (1989) Evaluation of Azadirachta indica leaf extract for hypoglycemic activity in rats. Phytother. Res. 3, 30-32.

Chattopadhyay RR. (1993) Possible mechanism of anti-hyperglycemic effect of Azadirachta indica leaf extract, part II. J. Ecobiol. 4, 309-312.

Chattopadhyay RR. (1996) Possible mechanism of anti-hyperglycemic effect of Azadirachta indica leaf extract, part IV. Gen. Pharmacol. 27, 431-434.

Chattopadhyay RR. (1999) Possible mechanism of anti-hyperglycaemic effect of Azadirachta indica leaf extract, part V. J. Ethnopharmacol. 67, 373-376.

Chattopadhyay RR, Chattopadhyay RN, Maitra SK. (1993b) Possible mechanism of anti-hyperglycemic effect of Azadirachta indica leaf extract, part III. Fitoterapia LXIV(6), 535-538.

Chattopadhyay RR, Chattopadhyay RN, Nandy A, Podder G, Maitra SK. (1987) Preliminary report on 
anti-hyperglycemic effect of a fraction of fresh leaves of Azadirachta indica (Beng. Neem). Bull. Calcutta Sch. Trop. Med. 35, 29-35.

Chattopadhyay RN, Maitra SK, Chattopadhyay RR. (1993a) Possible mechanism anti-hyperglycemic effect of Azadirachta indica leaf extract, part I. Fitoterapia LXIV(4), 332-336.

Dixit VP, Sinha R, Tank R. (1986) Effect of Neem seed oil on the blood glucose concentration of normal and alloxan diabetic rats. J. Ethnopharmacol. 17, 95-98.

Dubowski MK. (1962) Methods for body glucose determination. Clin.Chem. 8, 215-253.

El-Hawary ZM, Kholief TS. (1990) Biochemical studies on hypoglycemic agents (1), Effect of Azadirachta indica leaf extract. Arch. Pharmacol. Res. 13, 108-112.

Feldman JM, Libovitz HE. (1970) Mechanism of epinephrine and serotonin inhibition of insulin release in golden hamster in vitro. Diabetes 19, 480487.

Ghani K. (1920) Khazain ul-Advia Vol. III, p. 988-996, Nawal Kishore, Lucknow, india.

Gupta S, Kataria M, Gupta PK, Murganandan S, Yashroy RC. (2004) Protective role of extracts of neem seeds in diabetes caused by streptozotocin in rats. J. Ethnopharmacol. 90, 185-189.

Harborne JB. (1973) Phytochemical methods, p. 1-40, Chapman and Hall, London.

Hussain HEMA. (2002) Reversal of diabetic retinopathy in streptozotocin induced diabetic rats using traditional Indian anti-diabetic plant, Azadirachta indica (L). Indian J. Clin. Biochem. 17, 115-123.

Kaushik A, Saxena KK, Srivastava VK, Kumar A, Singh VS. (1999) Effect of alcoholic extract of Azadirachta indica (Neem) on blood glucose and lipid profile in experimentally induced diabetes. Indian J. Pharmacol. 31, 56.

Luscombe DK, Taha SA. (1974) Pharmacological Studies on the leaves of Azadirachta indica. J. Pharm. Pharmacol. 26, 111.

Murthy KS, Rao D.N, Rao DK, Murthy LBG. (1978) A preliminary study on hypoglycemic and antihyperglycemic effect of Azadirachta indica. Indian J. Pharmacol. 10, 247-250.

Nanduri S, Banstola P. (1995) Neeflone a new tetranortriterpenoid from Flowers of Azadirachta indica. Indian J. Chem. 34B, 1019-1020.

Pillai NR, Santhakumari G. (1981) Hypoglycemic activity of Melia azadirachta Linn (Neem). Indian J. Med. Res. 74, 931.

Purohit AK, Joshi VB, Pingle VS, Vyas SA. (1990) Hypoglycemic activity of Neem seed oil (Azadirachta indica) on streptozotocin induced diabetic mice. J. Diabetes Assoc. India 30, 36-37.

Rahman SZ, Jairajpuri S. (1996) Unani Medicine edited by NS Randhawa, BS Parmar, p. 256-267, New Age International (P) Ltd., Calcutta, India.

Santoshkumari KS, Devi KS. (1990) Hypoglycemic effect of a few medicinal plants. Ancient Sci. Life 9, 221-223.

Sha H, Zhao JB, Zhang ZY, Zhou SP, Tong XL, Zhuang FY, Gregersen H. (2006) Effect of Kaiyu Qingwei Jianji on the morphometry and residual strain distribution of small intestine in experimental diabetic rats. World J. Gastroenterol. 12, 7149-7154.

Sharma MK, Khare AK, Feroz H. (1983) Effect of Neem oil on blood sugar levels of normal hypoglycemic and diabetic animals. Indian Med. Gaz. Nov., 380383.

Siddiqui B, Siddiqui BS, Faizi S. (1986a) Studies on the Chemical constituents of Azadirachta indica-VII. Z. Naturforsch. 42B, 922-924.

Siddiqui B, Siddiqui BS, Faizi S, Mahmood T. (1986b). Isolation of triterpenoid from Azadirachta indica. Phytochemistry 25, 2183-2185.

Subramanian SS, Rangaswami S. (1947) Chemical Examination of the Flowers of Melia azadirachta. Curr. Sci. 16, 182-183.

Subramanian SS, Nair AGR. (1972) Melicitrin - A new myricetin glycoside from the flowers of Melia azadirachta. Indian J. Chem. 10, 452. 